\title{
RESEARCH
}

Open Access

\section{Recovery of bird communities following the construction of a large-scale hydroelectric dam}

Affan Nasruddin-Roshidi ${ }^{1}$, Mohammad Saiful Mansor ${ }^{1 *}$ D, Nor Adibah Ismail ${ }^{1}$, Ehwan Ngadi ${ }^{2}$, Mohd Izzat-Husna $^{1}$, Shahril Mod Husin ${ }^{3}$, Farah Shafawati Mohd-Taib', Rahmah Illias ${ }^{4}$ and Shukor Md Nor ${ }^{1}$

\begin{abstract}
Background: Habitat degradation is known to have a major impact on the composition of bird communities, yet how these communities recover following such disturbance is less understood. This study examined bird community changes from pre-logging to recovery over the course of habitat disturbance caused by the development of the Hulu Terengganu Hydroelectric Dam Project in Peninsular Malaysia, between 2007 and 2018. Bird surveys were conducted using point count observations and mist netting in the dam area from the prelogging phase until the operation phase.
\end{abstract}

Results: It was observed that while bird species significantly declined after large-scale habitat clearance between the pre-logging and construction phases, they showed positive signs of recovery from the inundation to operation phases. These findings indicate that the bird community is still recovering, and the permanent loss of habitat required by most of the original species has not occurred, as evidenced by recolonisation. Bird species composition differed across phases due to varying habitat conditions. The turnover rate and immigration rate (recolonisation and newly recorded species) were higher between the construction and operation phases. It was also observed that insectivorous birds were more heavily affected than others by changes to the landscape, which highlights the versatility, survivability and tolerance of certain species to extreme disturbance and habitat modification.

Conclusion: Although the operation phase showed an incremental change in bird species richness due to recolonisation and newly recorded species, this value remains far from that of the pre-logging phase. We predict that bird species recovery will continue to increase for some time before reaching a plateau among the newly created islands, reservoir and catchment area of the dam.

Keywords: Dam construction, Extinction, Habitat recovery, Recolonisation, Turnover

\footnotetext{
* Correspondence: msaifulmansor@gmail.com

'Department of Biological Sciences and Biotechnology, Faculty of Science and Technology, Universiti Kebangsaan Malaysia, 43600 Bangi, Selangor,

Malaysia

Full list of author information is available at the end of the article
}

\section{Springer Open}

(c) The Author(s). 2021 Open Access This article is licensed under a Creative Commons Attribution 4.0 International License, which permits use, sharing, adaptation, distribution and reproduction in any medium or format, as long as you give appropriate credit to the original author(s) and the source, provide a link to the Creative Commons licence, and indicate if changes were made. The images or other third party material in this article are included in the article's Creative Commons licence, unless indicated otherwise in a credit line to the material. If material is not included in the article's Creative Commons licence and your intended use is not permitted by statutory regulation or exceeds the permitted use, you will need to obtain permission directly from the copyright holder. To view a copy of this licence, visit http://creativecommons.org/licenses/by/4.0/. 


\section{Introduction}

As the global climate crisis continues to worsen, sustainable energy production is increasingly being considered an alternative to fossil fuels for meeting energy demands, which are projected to increase by $50 \%$ and $79 \%$ by 2030 (IRENA 2016) and 2050 (USEIA 2017), respectively. Developing countries require a growing and reliable energy supply to meet the demands of industry, domestic usage and agriculture. One source of renewable energy is hydroelectric power, which constitutes over $92 \%$ of the total renewable energy generated (Nowak et al. 2003) and supplies about 20\% of global electricity (Paish 2002). Hydroelectric power generation significantly reduces the burning of oil and coal for power generation (Bakis 2007); thus, it remains a popular renewable energy source.

Although hydroelectric power is considered a form of green energy, there are many detrimental impacts of hydropower plants-especially during construction and inundation phases. Hydroelectric dams can block nonvolant and aquatic animal migratory pathways, introduce alien species and flood surrounding lowland habitat (Lees et al. 2016; Gibson et al. 2017; Wu et al. 2019a). Furthermore, dam impoundments disrupt wildlife by altering the original environment, thereby hindering wild animals and plants from thriving due to the degradation or loss of habitat (Mohd-Taib et al. 2018). Dam construction also creates hilltop islands surrounded by water, which represents a more severe form of degradation than the fragmentation resulting from forest clearance for agricultural purposes. The islands and their isolated habitats respond differently from simple terrestrial fragmentation and pose an enormous threat to resulting habitat patches and the biodiversity within those patches (Wolfe et al. 2015). Constructing hydroelectric dams also modifies the landscape and habitat on a larger scale and affects wildlife both within and adjacent to the construction area. Extensive habitat modification of this type is considered a major factor contributing to the degradation of global species diversity (Laurance and Bierregaard 1997; Michalski et al. 2006).

An estimated 2 billion hectares of the earth's surface is degraded (Laestadius et al. 2011), with half of this degradation occurring in tropical countries, where logging and forest conversion to agriculture are the major causes of degradation (Thiollay 1992; Sodhi and Brook 2006). In Malaysia, forests are also disappearing for the same reasons (i.e., conversion action, agriculture and urban development activities) (Camara et al. 2019). Notably, habitat loss and fragmentation are considered the main causes of biodiversity loss worldwide. Fragmentation is a dynamic process that continuously reduces habitat into smaller pieces and results in isolation as well as the increased vulnerability of populations to edge effects
(McGarigal and Cushman 2002). Smaller forest areas increase isolation (Hanski and Hanski 1999) and edge effects, which significantly reduce species richness and genetic diversity (Dixo et al. 2009). Notably, a decrease in the genetic diversity of a species or population results in its increased susceptibility to disease (van Houte et al. 2016).

Birds have been commonly used in studies of environmental change (Gregory et al. 2009), ecological function (Slocum and Horvitz 2000) and habitat recovery (Šálek 2012). According to Pleguezuelos et al. (2012), birds are an excellent group of animals to assess restoration success in large-scale ecosystems because they are diverse, easily detected, and sensitive to changes in habitat structure and composition (Suárez-Seoane et al. 2002). Thus, changes in bird diversity may provide a rough estimation of current and future prospects of other organisms in shared habitats over time. Theoretically, disturbed areas have fewer species than pristine undisturbed habitats (Barlow et al. 2007). Following disturbance, species richness is expected to initially decline, but recolonisation may occur as long as the area and its surrounding habitats are improving (Karr 2002) and there is adequate relatively undisturbed forest nearby to provide seed populations for the rehabilitation of the affected areas.

Numerous studies have documented the disappearance of bird species occurring in forest fragments in tropical regions worldwide (Newmark 1991). However, how such changes occur over the course of hydroelectric dam development in tropical regions remains unclear. The present study represents the first time that changes in bird assemblages due to a large-scale hydroelectric dam project have been monitored from the pre-logging (PL), logging (LG), construction (CN), and inundation (IN) phases to recovery during the operation (OP) phase in Peninsular Malaysia. Specifically, this study focuses on the effects of ecosystem degradation in and adjacent to the Hulu Terengganu Hydroelectric Dam on bird species diversity and recovery processes across the project's progression from the PL to OP phases. We hypothesised that bird species richness will recover during the OP phase after severely declining in the LG and $\mathrm{CN}$ phases to reach a species number similar to the PL phase, but with different species composition due to alteration of the original habitat. The turnover rate was also hypothesised to be higher across study phases. It was also hypothesised that insectivorous birds would be the most affected guild due to their sensitivity to habitat disturbance.

\section{Materials and methods}

\section{Study area}

This study was conducted in Puah Catchment, Hulu Terengganu $\left(5.150396^{\circ} \mathrm{N}, 102.359811^{\circ} \mathrm{E}\right)$, which is located 
approximately $120 \mathrm{~km}$ northwest of Kuala Terengganu, Peninsular Malaysia (Fig. 1). The Hulu Terengganu Hydroelectric Project (HTHEP) is located in Tembat Forest Reserve and Petuang Forest Reserve in Hulu Terengganu District. The HTHEP consists of two hydroelectric dams, namely Puah Dam and Tembat Dam, which supply $250 \mathrm{MWh}$ and $25 \mathrm{MWh}$, respectively with approximately 50,611 ha catchment area.

Prior to logging for the HTHEP, the Department of Wildlife and National Park Peninsular Malaysia (PERH ILITAN) has conducted a wildlife survey including avifauna in 2007 during PL phase (PERHILITAN 2007). The selective logging process took approximately 4 years around Puah Reservoir. Approximately $190 \mathrm{~km}^{2}$ of forested area was logged between 2010 and 2014 (Magintan et al. 2019). The CN phase began in 2012, and the IN phase occurred from October 2014 until September 2015 , and an approximately $61 \mathrm{~km}^{2}$ reservoir was formed in the process, including an estimated 27 landbridge islands being formed by 2015 . The water level slowly increased during the IN phase to make way for animals to move out of the catchment area and onto newly created islands within it. The OP phase began right after the water level reached a desired depth $( \pm 290$ $\mathrm{m}$ above sea level).

The forests on most of the created land-bridge islands were selectively logged prior to the IN phase, which area $320 \mathrm{~m}$ a.s.l. was logged and some of matured forest tree individuals such as from the family Dipterocarpacae were left intact. Several islands (higher elevation) were left intact with matured forest trees, while cleared area was now dominated with pioneer tree species, comprising of 20 tree species $(\mathrm{DBH}>1 \mathrm{~cm})$ such as Rubiaceae and Euphorbiaceae. We analysed the satellite images from year 2007 to 2020 using Google Earth. The logged area was from approximately 8096 ha in PL to 10,399 ha in LG to 15,199 ha in $\mathrm{CN}$, and reduced to 6100 in OP upon habitat recovery with pioneer species and replanting programme.

\section{Bird surveys}

Birds were censused from January 2017 until August 2018, during the dam operation phase, in the Puah catchment area. We used a standard line transect method (Bibby et al. 2000) at fixed locations. Several line transects were established and surveyed every month in mainland area (6 transects) and created islands (1 transect per island). The length of the transects varied from 300 to $1200 \mathrm{~m}$, and each transect was separated from the others by approximately $400 \mathrm{~m}$ (Mansor et al. 2020). Each transect was sampled six times (one to two times per month) over the study period. Birds were observed throughout the day (between 07:30 and 18:30), but mostly in the early morning and late afternoon. Most sampling transects were established along former logging roads used to transport timber from the logging site. For comparison, we used data from previous studies conducted at same the logging trails and used the same

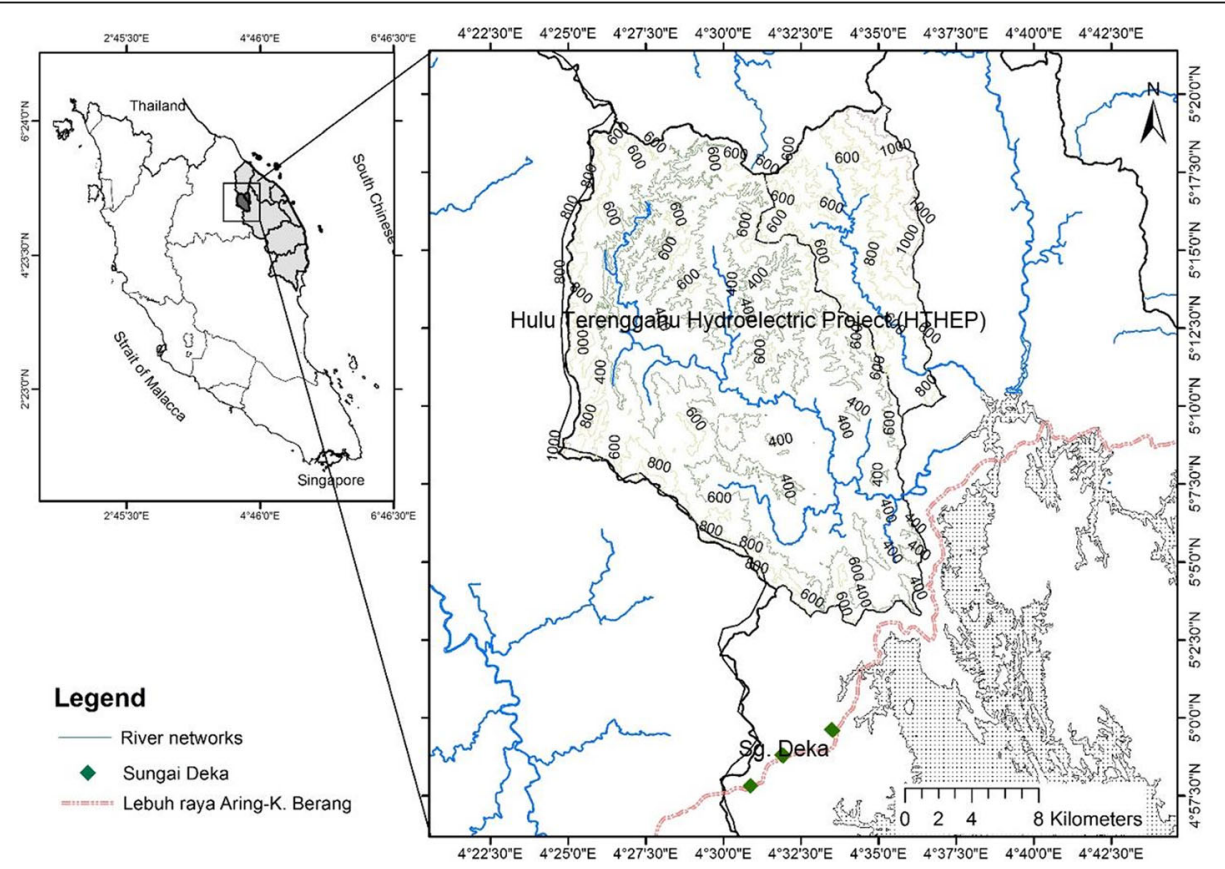

Fig. 1 The location of study site: Hulu Terengganu Hydroelectric Project (HTHEP), Terengganu, Peninsular Malaysia. The inset map shows the preinundation phase of Puah Catchment area with tributaries is still visible 
methods, particularly during the PL phase (PERHILIT AN 2007), LG phase (Aziz 2013), CN phase (Jamaluddin 2015) and IN phase (Ibrahim 2016; Mohd-Taib et al. 2018). Some transects that disappeared due to the inundation process were conducted on nearby created landbridge islands. Additionally, 10 mist nets were erected at each study site for 4 days per sampling session. These mist nets were randomly placed each month to prevent birds from becoming familiar with mist net locations.

\section{Data analysis}

To show the pattern of the species change in each phase of dam development, a simple line graph of the species number was plotted based on presence-absence data. Species turnover rate was calculated using formula adapted from Diamond (1969) to show the dynamic of species extinction and immigration occurring throughout phases. We assumed there is no human-introduced species in the study area as it is prohibited area and located further from nearest human settlements $( \pm 35 \mathrm{~km}$ to Kampung Basong).

A dendrogram of species composition based on Jaccard similarity and single-linkage clustering (Niwattanakul et al. 2013) was then plotted using the PAST software package (Paleontological Statistics) vers. 2.17 (Hammer et al. 2001). The dendrogram indicates the species similarity between the phases and how the species composition changed from phase to phase in response to the habitat modification. Three-dimensional non-metric multidimensional scaling (3D-nMDS) was also applied to determine the similarity and dissimilarities of bird communities between phases of PL, LG, CN, IN and OP. Similar development phases were grouped into the same branch with high similarity value on single-linkage dendrogram using PRIMER-E version 7 (Clarke and Gorley 2017). To measure beta diversity $(\beta)$ across phases at the landscape level, we used Whittaker pairwise (Global beta diversity $=1.29$ ).

The species richness of bird communities across the study phases was computed using average taxonomic distinctness (AvTD) and variation in taxonomic distinctness (VarTD). AvTD analysis is useful for measuring the mean distance between two randomly selected species using presence-absence data (Warwick and Clarke 1995). On the other hand, VarTD is the branch length variation among all species pairs. VarTD also acts as a measure of irregularity and divergence for the branch length distribution within a sample (Tolimieri and Anderson 2010). This method is highly sensitive to changes in community composition (Schweiger et al. 2008) and provides statistically powerful summaries of taxonomic relatedness patterns within bird assemblages (Clarke and Warwick 2001). AvTD not only represents species richness per se but also considers the elimination and addition of higher taxonomic ranks (e.g., family and order). AvTD indicates the pairwise distance within a taxonomic ranking, and its values decrease if there is an absence of an element in taxonomic ranking. The greater the taxonomic ranking difference among phases, the more significant the decrease in AvTD value. Instead of measuring the changes in species number, these tests measure changes in taxonomic level and provide more information on the actual impact of the various developmental phases on bird communities in the Puah Lake Catchment. These analyses were computed using the PRIMER-E software version 7 (Clarke and Gorley 2017).

\section{Results}

A total of 282 bird species representing 64 families were recorded across dam development phases (Supplementary Table 1). The most dominant bird group at all phases was flycatchers (Muscicapidae; 23 species), followed by babblers (Timaliidae and Pellorneidae; 22 species), bulbuls (Pycnonotidae; 19 species), cuckoos (Cuculidae; 17 species) and spiderhunters and sunbirds (Nectariniidae; 15 species). The PL phase had the highest number of species (250 species, Fig. 2). This number declined in the LG by $53 \%$ to 117 species and severely declined during $\mathrm{CN}$ and IN phases (64 and 87 species, respectively). However, the number of species increased by $45 \%$ during the OP phase (126 species) from IN phase. Approximately $11 \%$ of total bird species were observed at all phases, while $30 \%$ of recorded species were unique to one phase only. During the $\mathrm{CN}$ phase, all species in the Accipitridae (hawks and eagles), Bucerotidae (hornbills) and Megalaimidae (Barbets) families that were previously present disappeared. During the OP phase, new species emerged that were absent in previous phases such as Malaysian Hawk Cuckoo Hierococcyx fugax, Scarlet Minivet Pericrocotus speciosus and Tickell's Blue Flycatcher Cyornis tickelliae. Turnover rate and immigration rate (recolonisation and newly recorded species) were higher between construction and operation phases (Table 1).

Cluster analysis grouped PL and LG, and IN and OP, and the 3D-nMDS analysis also clustered these two pairs of phases, and the $\mathrm{CN}$ phase was outlier from the both groups (Fig. 3). PL-LG and IN-OP had somewhat similarity value, 0.377 and 0.364 , respectively. The outlier group, $\mathrm{CN}$, had a rather different species composition in which the number of species recorded was at the lowest compared to all other phases. This analysis was consistent with the beta diversity $(\beta)$ of bird communities across phases at the landscape level (Table 2). Grouped phases in cluster analysis had low $\beta$ value, indicating high shared species composition between the two phases. A drastic change in species composition between $\mathrm{PL}$ and $\mathrm{CN}$ phases was indicated by the highest $\beta$ value, 


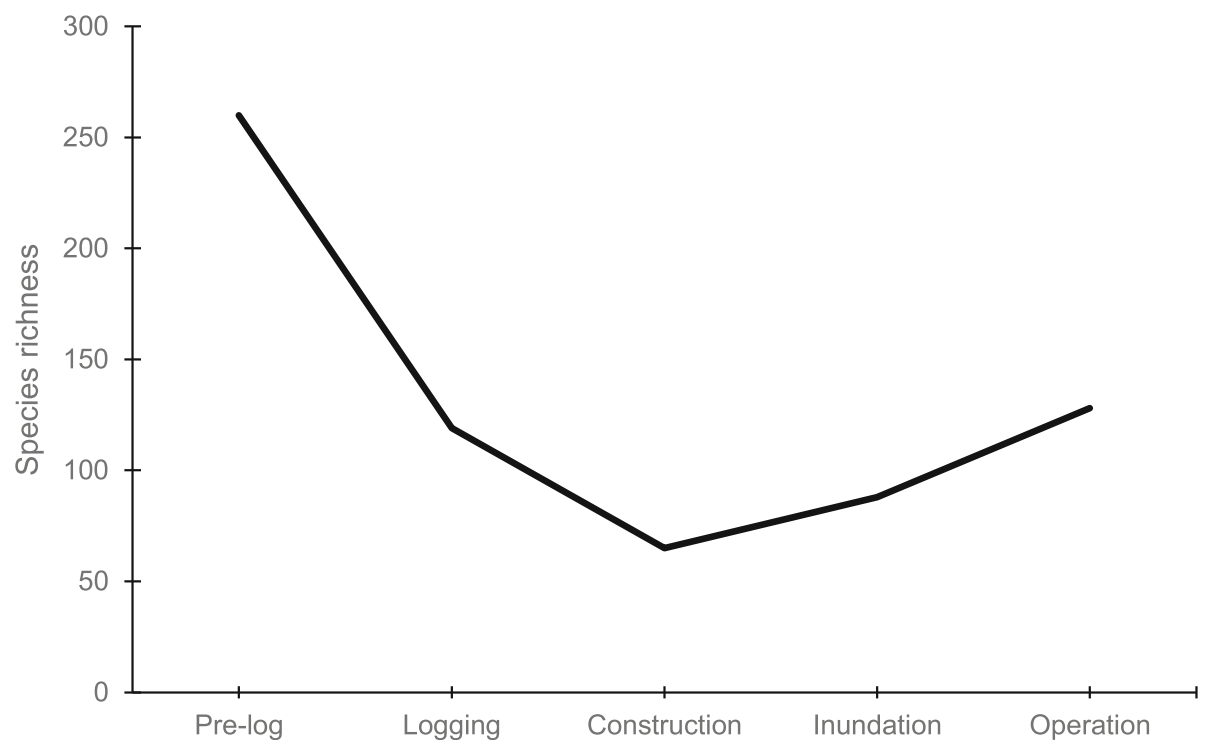

Fig. 2 The bird species richness plotted against dam development phases throughout 10 years study in Puah Lake Catchment, Hulu Terengganu, Peninsular Malaysia

0.6384, while the least changes occurred between phases PL and LG $(\beta=0.4609)$.

Insectivores and frugivores make up the major feeding guilds in study areas (Fig. 4), particularly 63\% (179 species) as insectivores, $19 \%$ (54 species) as frugivores, $9 \%$ (26 species) as carnivores, 5\% (15 species) as nectarivores and $2 \%$ (six species) as granivores. Insectivores (KruskalWallis; $H=137.4, d f=4, P<0.05)$ and frugivores $(H=$ 128.6, $d f=4, P<0.05$ ) were the only feeding guilds that differ significantly across study phases. A drastic drop of insectivore species can be seen in $\mathrm{CN}$ phase (44 species) from 163 species in PL phase. However, insectivore species started to increase in IN phase (54 species) and further in OP phase (80 species), which is consistent with overall species richness fluctuation trend in Fig. 2. For example, babblers, insectivores, in the PL phase (21 species) were reduced during the LG phase (17 species), CN phase (12 species) and IN phase (11 species), though slightly increased in the OP phase (13 species) (Supplementary Table 1).

AvTD values produced a decreasing pattern from PL to $\mathrm{LG}$ to $\mathrm{CN}$ phases (Table 3). However, the AvTD value starts to increase from IN to OP. These values showed a positive correlation but not significant with the number of species in the communities in all phases $(r=0.738, p$ $=0.154$ ). VarTD shows the opposite pattern value, in which the values increase from early PL to LG, and then increase more towards $\mathrm{CN}$ (Table 3). It starts to decrease from $\mathrm{CN}$ to IN and continues decreasing to OP. VarTD values indicated a negative correlation but not significant with the number of species in the communities in all phases $(\mathrm{r}=-0.741, p=0.152)$.

\section{Discussion}

Bird species richness rapidly decreased after the PL phase until reaching the lowest levels during the $\mathrm{CN}$ phase. Thereafter, it began to increase gradually during the IN and OP phases. The disappearance of certain higher taxonomic levels (i.e., order, family) and species after the PL phase (AvTD = 72.46) was due to logging activities before the construction of the hydroelectric dam (from the PL phase to the $\mathrm{CN}$ phase). Notably, there was a significant correlation between habitat degradation and decreasing species richness $(P<0.05)$. For

Table 1 Bird species richness changes: shared species, local extinction, immigration and turnover rate, throughout the dam development phases in Puah Lake Catchment, Hulu Terengganu, Peninsular Malaysia. Abbreviations: PL pre-log, CN construction, IN inundation, $O P$ operation

\begin{tabular}{llllll}
\hline Phase & PL-IN & PL-OP & CN-IN & CN-OP & IN-OP \\
\hline Shared species & 80 & 107 & 40 & 39 & 59 \\
Extinction & 194 & 169 & 67 & 28 & 33 \\
Immigration (recolonisation/newly recorded) & 10 & 24 & 25 & 62 & 23 \\
Turnover rate & $61 \%$ & $51 \%$ & $63 \%$ & $26 \%$ \\
\hline
\end{tabular}




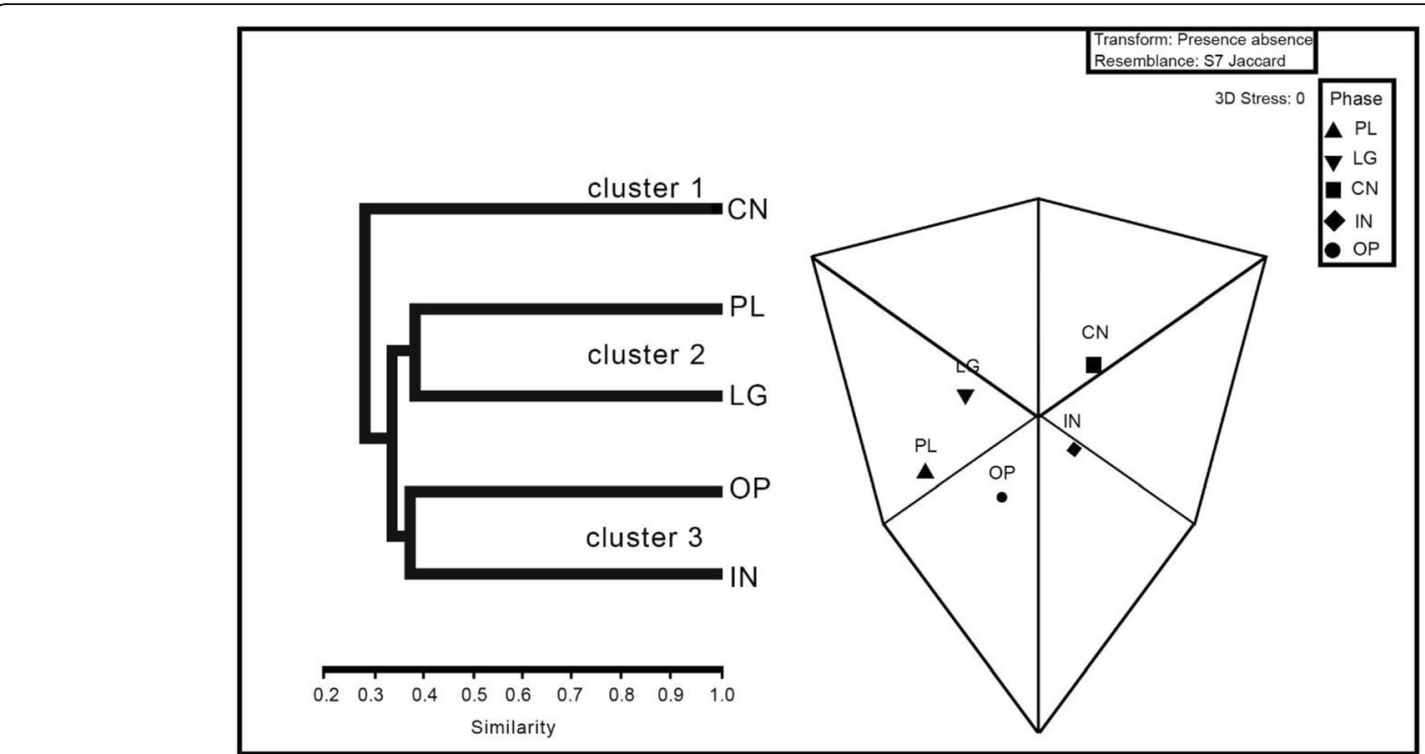

Fig. 3 Cluster analysis and three-dimensional non-metric multidimensional scaling (3D-NMDS) plot of Jaccard similarity matrixes showing the distribution of bird communities according to phases in Puah Lake Catchment, Hulu Terengganu, Peninsular Malaysia. The good quality of the ordination is indicated by a low stress value $(3 D$ stress $=0$ ). Abbreviations: $P L$ pre-log, $L G$ logging, CN construction, IN inundation, $O P$ operation

example, the eradication of the Paridae and Sittidae families-each of which consisted of a single species (Sultan Tit Melanochlora sultanea and Velvet-fronted Nuthatch Sitta frontalis, respectively)-occurred after the PL phase. Bird species that disappeared after the PL phase included the Malaysian Rail Babbler Eupetes macrocerus, Jambu Fruit Dove Ptilinopus jambu and Garnet Pitta Erythropitta granatina, which contributed to the lower AvTD values after the PL phase. The lowest species diversity and AvTD values were observed during the $\mathrm{CN}$ phase (AvTD = 65.38), as evidenced by the absence of several bird families and migratory birds, including the Meropidae (Blue-tailed Bee-eater Merops philippinus), Motacillidae (Grey Wagtail Motacilla cinerea) and Laniidae (Tiger Shrike Lanius tigrinus and Brown Shrike Lanius cristatus). Since migratory birds must consume ample food to meet their energy demands, the degraded

Table 2 Beta diversity ( $\beta$ ) of bird communities' similarity at landscape level across dam development phases in Puah Lake Catchment, Hulu Terengganu, Peninsular Malaysia. The highervalue means the more dissimilarity of one phase to its paired phase. Abbreviations: PL pre-log, LG logging, CN construction, IN inundation, OP operation

\begin{tabular}{lllll}
\hline & PL & LG & CN & IN \\
\hline LG & 0.4609 & & & \\
CN & 0.6384 & 0.5744 & & \\
IN & 0.5543 & 0.4929 & 0.4968 & \\
OP & 0.4742 & 0.4761 & 0.6060 & 0.4708 \\
\hline
\end{tabular}

habitat was likely unsuitable for migratory stopovers (McKinney 2002), which might explain the absence of these migratory birds during the $\mathrm{CN}$ phase. However, species diversity and AvTD values began to increase gradually after the $\mathrm{CN}$ phase, during the IN (AvTD = 68.66) and OP phases (AvTD = 71.66). This pattern of increase was due to the recolonisation and introduction of newly recorded bird species that were not previously observed. For example, the re-emergence of both shrike species in the OP phase indicates that the catchment began to attract migrants to the area once again. Furthermore, the positive trend following the IN phase suggests that bird species richness began to increase in accordance with habitat age and heterogeneity (Šálek 2012). From the IN to OP phase, the open area (i.e., not covered by vegetation) decreased from 18,000 ha (35\% of the total catchment area) to only 6100 ha (12\%). Forest remnants with no human interference at a higher elevation in the area also contributed to the increase in bird species richness during the OP phase.

Species diversity and AvTD values are expected to increase further as the forest regenerates enough to provide habitat and feeding opportunities that cater to a greater number of bird species; however, we expect that it will be dominated by coloniser species such as spiderhunters and bulbuls during early forest regeneration (Hashim and Ramli 2013). The ability of bulbuls to switch their diet to insectivory makes them more adaptable to disturbances and the absence of seasonal fruits (Zakaria and Francis 2001). Bulbuls are generalist species and are typically replaced by more forest-dependent 


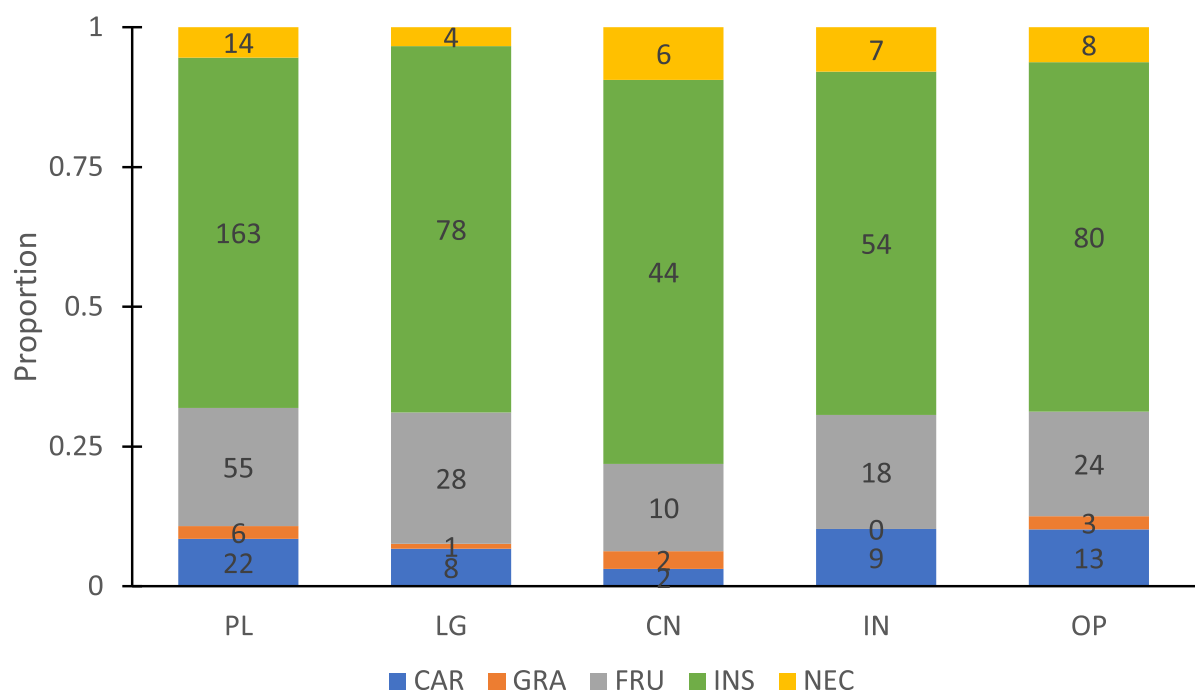

Fig. 4 Histogram plot of bird species according to their respective feeding guild throughout the study phases in Puah Lake Catchment, Hulu Terengganu, Peninsular Malaysia. $y$-axis indicates the proportion of each feeding guild's species richness in its respective phase. The number on each bar represents the actual species richness of each feeding guild in each phase. Abbreviations: PL pre-log, LG logging, CN construction, IN inundation, OP operation, CAR carnivore, FRU frugivore, GRA granivore, INS insectivore, NEC nectarivore

species upon habitat recovery (Zakaria and Nordin 1998). For example, thirteen bulbul species from IN phase was reduced to 10 species in the OP phase, while the number of babbler species increased from 11 to 13 across both phases. Temporal changes in forest structure show increasing tree species density at the forest edge, ridges and islands from 2016 to 2017 (Abd Razak et al. 2019). The mass immigration (72 bird species) and low local extinction (33 bird species) between these two phases might indicate that the habitat has now become more stable and can support a higher number of species.

The most diverse bird group recorded in PL phase was babblers from Timaliidae and Pellorneidae families; however, their diversity declined across subsequent phases and slightly increased in the OP phase. Babblers are primarily insectivorous, and their decrease in number is likely due to reduced arthropod prey abundance in changing microclimate (Wong 1985; Yong et al. 2011; Mansor et al. 2019). Furthermore, insectivorous birds are also prone to the competition with opportunistic, disturbance-adapted omnivores (Canaday 1996) across dam construction phases. Most babbler species are also confined to the forest interior and have relatively limited distributions; therefore, they are likely sensitive to habitat disturbance (Styring et al. 2016; Mansor et al. 2018). These ecological explanations regarding the sensitivity of insectivores were supported by the present study, where the number of insectivorous birds was reduced after the PL phase but increased during the IN phase, and then increased further during the OP phase. The extreme inter-phase fluctuation in insectivorous bird species richness made them the feeding guild most heavily affected by forest fragmentation, which is consistent with many previous research (Stouffer and Bierregaard Jr 1995; Şekercioḡlu 2002; Sodhi et al. 2004). Their highly specific feeding strategy for obtaining prey also contributes to the sensitivity of insectivorous birds since their prey actively avoids predation (Şekercioğlu 2002; Mansor et al. 2015).

Frugivorous birds also followed a similar trend of decreasing species richness after the PL phase; however, this began to increase during the IN phase and increased

Table 3 Average taxonomic distinctness (AvTD) and variation in taxonomic distinctness (VarTD) values across dam development phases throughout 10 years study in Puah Lake Catchment, Hulu Terengganu, Peninsular Malaysia, calculated using the PRIMER-E software. Abbreviations: PL pre-log, LG logging, CN construction, IN inundation, OP operation

\begin{tabular}{llllll}
\hline Phase & Species & AvTD value & AvTD Sig \% & VarTD value & VarTD Sig \% \\
\hline PL & 250 & 72.46 & 5.8 & 139.83 & 0.8 \\
LG & 117 & 71.67 & 13.4 & 149.33 & 3.0 \\
CN & 64 & 65.38 & 0.2 & 179.26 & 0.2 \\
IN & 87 & 68.66 & 0.2 & 173.88 & 0.2 \\
OP & 125 & 71.66 & 12.2 & 139.13 & 46.2 \\
\hline
\end{tabular}


further during the OP phase. The absence and presence of frugivores can be highly correlated with the maturity of forests due to the higher availability of fruiting trees in more mature forests. For example, given the increasing number of frugivorous birds during the OP phase, the absence of hornbill species such as the Great Hornbill Buceros bicornis and Rhinoceros Hornbill Buceros rhinoceros during the OP phase was likely the result of high disturbance in the Puah Catchment area, particularly due to the loss of large trees logged for construction purposes. Notably, such trees are preferred by these species for both nesting and fruit consumption (Kinnaird and O'Brien 2007). Moreover, larger bird species tend to be more heavily affected by logging (Hammers et al. 2015; Constantini et al. 2016). However, sightings of Oriental Pied Hornbill Anthracoceros albirostris continued to increase from the $\mathrm{CN}$ to $\mathrm{OP}$ phases, which was likely due to their resilience to habitat disturbance, fragmentation and degradation (Datta 1998). The recolonisation of more frugivorous species in the OP phase represents a positive sign of forest maturity. These findings are consistent with Styring et al. (2011), who noted that bird communities become more evenly distributed in more mature forests since they provide numerous niches for birds.

However, the percentages of both granivores and nectarivores exhibited the inverse of the general species recolonisation trend, which was highest during the $\mathrm{CN}$ phase (granivores 3\%; nectarivores 10\%) since more open habitats were created after the extensive logging process in 2009. These habitats are preferred by granivorous birds due to their large seed bank availability (Diaz and Telleria 1996; Chettri et al. 2005). While granivores are known to increase in number immediately after logging, granivore populations eventually decline when their preferred grasslands are replaced by more complex forest regrowth during the recovery process (Burivalova et al. 2015). Furthermore, nectarivores also followed a similar trend to granivores since they decreased in accordance with the maturity of the forest, particularly decreased during the IN phase (8\%) and then decreased further during the OP phase (6\%). High nectarivore numbers are usually recorded in the early regeneration phase of a forest due to their preference for pioneer plant species such as those from the Musaceae and Zingiberaceae families, which easily proliferate after logging (Johns 1989).

The similarity of species composition between the PL and LG phases suggests that the species recorded during the LG phase were not fully extirpated due to selective logging practices in area. The similar species composition observed during the $\mathrm{OP}$ and IN phases suggests that the water matrix created as the result of landscape modification during the IN phase gave rise to the influx of new opportunist species that are better adapted to such habitats, such as the piscivorous Purple Heron Ardea purpurea, White-bellied Sea Eagle Haliaeetus leucogaster and Osprey Pandion haliaetus, which forage for fish in the dam reservoir. The number of species from the Ardeidae family also increased during the OP phase when compared to the PL phase. Wu et al. (2021) suggested that members of the Ardeidae family prefer shallow waters but dislike sandy areas that are likely abundant during the PL phase in which riverbank was not yet inundated. These findings suggest that bird species assemblages were primarily influenced by the habitat type available to them and largely motivated by food availability (Sohil and Sharma 2020). Notably, different land cover types will provide different habitats and food (Wu et al. 2019b). As such, these species may have replaced previous forest-dependent species. Since the inundation process created a water barrier and fragmented the forested area, insectivorous forest birds-which prefer a closed-canopy habitat and are weak dispersers that are unable to fly across $100 \mathrm{~m}$ of open water-experienced a dispersal barrier (Moore et al. 2008; Mansor et al. 2018) that hindered their recolonisation and migration to forest patches from the surrounding mainland.

\section{Conclusions}

Following a severe decline from the PL to $\mathrm{CN}$ phases, the OP phase exhibited a significant increase in bird species richness. This suggests that the vegetation of the study area has become more stable, with certain species beginning to recolonise and newly emerged. Species richness is projected to increase further due to greater habitat stability and more diverse vegetation that will soon flourish around the Puah Catchment and attract more bird species to the area. Notably, two projects aimed at replanting tree seedlings in the Puah Catchment area have been completed to hasten the recovery process. Nine families of forest tree species were chosen for replanting purposes and have been maintained by hired contractors to ensure the survival of planted trees. The biodiversity value of regenerating forests suggests that the species richness in disturbed forests will recover to a pre-disturbed state within 20-40 years of habitat disturbance (Dunn 2004). A further study within the next 5 or 6 years will be valuable to compare the recovery effect against the present data. Such findings can contribute towards understanding the detrimental effects of large-scale hydroelectric dam construction on the avian community and their recovery process. Impact assessments from all phases of this dam development can be referenced when constructing future sustainable hydroelectric dams. Using this information, developers and environmental consultants can develop optimal and effective mitigation plans for future dam developments in Malaysia and other developing countries. 


\section{Abbreviations}

AvTD: Average taxonomic distinctness; a.s.l: Above sea level; CAR: Carnivore; CN: Construction; DBH: Diameter at breast height; FRU: Frugivore; GRA: Granivore; HTHEP: Hulu Terengganu Hydroelectric Project: IN: Inundation; INS: Insectivore; LG: Logging; NEC: Nectarivore; OP: Operation; PERHILITAN: Department of Wildlife and National Park Peninsular Malaysia; PL: Pre-logging; VarTD: Variation in taxonomic distinctness; 3D-nMDS: Threedimensional non-metric multidimensional scaling

\section{Supplementary Information}

The online version contains supplementary material available at https://doi. org/10.1186/s13717-021-00298-1

Additional file 1: Supplementary Table 1. The presence-absence list of all bird species recorded across all study phases. Abbreviations: CAR, carnivore; FRU, frugivore; GRA, granivore; INS, insectivore; NEC, nectarivore; $\mathrm{PL}$, pre-logging phase; LG, logging phase; $C N$, construction phase; $\mathrm{IN}$, inundation phase; $\mathrm{OP}$, operation phase.

\section{Acknowledgements}

We thank the Department of Wildlife and National Park (PERHILITAN 2007) for their permission to perform this research. We also thank Zulkifli Khalid, Hussin Musa, Farid, Muhaidi Khalid and others for field assistance.

\section{Authors' contributions}

ANR, MSM, NAI, FSMT and RI collected the field data. MSM and SMN conceptualised the study design. ANR, EN and MIH analysed the data. SMH and SMN managed project administration. ANR and MSM led the manuscript writing. The authors read and approved the final manuscript.

\section{Funding}

This wildlife research was funded by Tenaga Nasional Berhad Research (TNBR), grant number ST-2017-010.

\section{Availability of data and materials}

The bird species checklist is provided as supplementary file.

\section{Declarations}

\section{Ethics approval and consent to participate}

Field studies were conducted in accordance and collaboration with the Department of Wildlife and National Park Peninsular Malaysia (PERHILITAN 2007). Photographic records were collected using a telephoto lens and binocular.

\section{Consent for publication}

Not applicable

\section{Competing interests}

The authors declare that they have no competing interest.

\section{Author details}

'Department of Biological Sciences and Biotechnology, Faculty of Science and Technology, Universiti Kebangsaan Malaysia, 43600 Bangi, Selangor, Malaysia. ${ }^{2}$ Kolej GENIUS Insan, Universiti Sains Islam Malaysia, Bandar Baru Nilai, 71800 Nilai, Negeri Sembilan, Malaysia. ${ }^{3}$ TNB Research Sdn Bhd, No. 1, Kawasan Institusi Penyelidikan, Jalan Ayer Itam, 43000 Kajang, Selangor, Malaysia. ${ }^{4}$ Department of Wildlife and National Parks (PERHILITAN), Km.10, Jln Cheras, 56100 Kuala Lumpur, Wilayah Persekutuan, Malaysia.

Received: 4 December 2020 Accepted: 8 April 2021 Published online: 07 May 2021

\section{References}

Abd Razak SN, Ahmad WJ, Noh NAl, Nasir NA, Shukor AMN, Shukor MD (2019) Regeneration of degraded lowland dipterocarp forest: elephants as seed dispersal agent. In: Sidek LM, Salih GHA, Boosroh MH (eds) Water resources development and management. Springer, Singapore
Aziz UM (2013) Species composition and richness of vertebrates (herpetofauna, birds, small mammals) at Hulu Terengganu, Peninsular Malaysia. Dissertation. Universiti Kebangsaan Malaysia

Bakis R (2007) Electricity production opportunities from multipurpose dams (case study). Renew Energy 32(10):1723-1738. https://doi.org/10.1016/j.renene.2 006.08.008

Barlow J, Mestre LAM, Gardner TA, Peres CA (2007) The value of primary, secondary and plantation forests for Amazonian birds. Biol Conserv 136(2): 212-231. https://doi.org/10.1016/j.biocon.2006.11.021

Bibby CJ, Burgess ND, Hill DA, Mustoe S (2000) Bird census techniques. Elsevier, London

Burivalova Z, Lee TM, Giam X, Şekercioğlu ÇH, Wilcove DS, Koh LP (2015) Avian responses to selective logging shaped by species traits and logging practices. Proc Royal Soc B 282(1808):20150164

Camara M, Jamil NR, Abdullah AFB (2019) Impact of land uses on water quality in Malaysia: a review. Ecol Process 8:10

Canaday C (1996) Loss of insectivorous birds along a gradient of human impact in Amazonia. Biol Conserv 77(1):63-77. https://doi.org/10.1016/0006-32 07(95)00115-8

Chettri N, Deb DC, Sharma E, Jackson R (2005) The relationship between bird communities and habitat. Mt Res Dev 25(3):235-243. https://doi.org/10.1659/ 0276-4741(2005)025[0235:TRBBCA]2.0.CO;2

Clarke KR, Gorley RN (2017) PRIMER v7: User Manual/Tutorial. PRIMER-E, Plymouth

Clarke KR, Warwick RM (2001) A further biodiversity index applicable to species lists: variation in taxonomic distinctness. Mar Ecol Prog Ser 216:265-278. https://doi.org/10.3354/meps216265

Constantini D, Edwards DP, Simons MJ (2016) Life after logging in tropical forests of Borneo: a meta-analysis. Biol Conservation 196:182-188. https://doi.org/1 0.1016/j.biocon.2016.02.020

Datta A (1998) Hornbill abundance in unlogged forest, selectively logged forest and a forest plantation in Arunachal Pradesh, India. Oryx 32(4):285-294 https://doi.org/10.1046/j.1365-3008.1998.d01-58.x

Diamond J (1969) Avifaunal equilibria and species turnover rates on the Channel Islands of California. Proc Natl Acad Sci 64(1):57-63. https://doi.org/10.1073/ pnas.64.1.57

Diaz M, Telleria JL (1996) Granivorous birds in a stable and isolated open habitat within the Amazonian rainforest. J Trop Ecol 12:419-425

Dixo M, Metzger JP, Morgante JS, Zamudio KR (2009) Habitat fragmentation reduces genetic diversity and connectivity among toad populations in the Brazilian Atlantic Coastal Forest. Biol Conserv 142(8):1560-1569. https://doi. org/10.1016/j.biocon.2008.11.016

Dunn RR (2004) Recovery of faunal communities during tropical forest regeneration. Conserv Biol 18(2):302-309. https://doi.org/10.1111/j.1523-173 9.2004.00151.x

Gibson L, Wilman EN, Laurance WF (2017) How green is 'green'energy? Trends Ecol Evol 32(12):922-935. https://doi.org/10.1016/j.tree.2017.09.007

Gregory RD, Green RE, Couvet D, Willis SG, Huntley B, Voříšek P, Collingham YC (2009) An indicator of the impact of climatic change on European bird populations. PLoS ONE 4:e46a78

Hammer O, Harper D, Ryan P (2001) PAST: Paleontological Statistics Software package for education and data analysis. Palaeontol Electron 4(1):1-9

Hammers M, Müskens GJ, van Kats RJ, Teunissen WA, Kleijn D (2015) Ecological contrasts drive responses of wintering farmland birds to conservation management. Ecography 38(8):813-821. https://doi.org/10.1111/ecog.01060

Hanski I (1999) Metapopulation ecology. Oxford University Press, Oxford

Hashim NE, Ramli R (2013) Comparative study of understorey birds diversity inhabiting lowland rainforest virgin jungle reserve and regenerated forest. Sci World J 2013:676507

Ibrahim MS (2016) Species composition and richness of bird assemblages at Hulu Terengganu, Peninsular Malaysia. Dissertation, Universiti Kebangsaan Malaysia

IRENA (2016) REmap: Roadmap for a Renewable Energy Future. International Renewable Energy Agency

Jamaluddin Ml (2015) Impacts of dam impoundment to the diversity, composition and body condition of birds in Hulu Terengganu. Dissertation Universiti Kebangsaan Malaysia

Johns AD (1989) Timber, the environment and wildlife in Malaysian rainforests. Final report to the Institute of Southeast Asian Biology, University of Aberdeen, Scotland

Karr JR (2002) Avian extinction on Barro Colorado Island, Panama: a reassessment. Am Nat 119:220-239 
Kinnaird MF, O'Brien TG (2007) The ecology and conservation of Asian hornbills: farmers of the forest. University of Chicago Press, Chicago

Laestadius L, Maginnis S, Minnemeyer S, Potapov P, Saint-Laurent C, Sizer N (2011) Mapping opportunities for forest landscape restoration. Unasylva 62:1-

Laurance WF, Bierregaard RO (1997) Tropical forest remnants: ecology, management, and conservation of fragmented communities. University of Chicago Press, Chicago

Lees AC, Peres CA, Fearnside PM, Schneider M, Zuanon JA (2016) Hydropower and the future of Amazonian biodiversity. Biodivers Conserv 25(3):451-466. https://doi.org/10.1007/s10531-016-1072-3

Magintan D, Salman S, Tukimat L, Shahril MH, Aisah MS, Shukor MN (2019) Impacts of Hulu Terengganu Hydroelectric Project on elephant movements and home range. In: Sidek LM, Salih GHA, Boosroh MH (eds) Water resources development and management. Springer, Singapore

Mansor MS, Nor SM, Ramli R (2020) Shifts in foraging behaviour of heterospecific flocking birds in a lowland Malaysian rainforest. Behav Processes 180:104229. https://doi.org/10.1016/j.beproc.2020.104229

Mansor MS, Nor SM, Ramli R, Sah SAM (2018) Niche shift in three foraging insectivorous birds in lowland Malaysian forest patches. Behav Processes 157 73-79. https://doi.org/10.1016/j.beproc.2018.09.001

Mansor MS, Ramli R, Sah SAM (2015) The foraging tactics of Chestnut-winged babbler (Stachyris erythroptera) and Abbott's babbler (Malacocincla abbotti) in a lowland rainforest, Malaysia. Sains Malays 44(5):687-692. https://doi.org/10.1 7576/jsm-2015-4405-07

Mansor MS, Rozali FZ, Abdullah NA, Nor SM, Ramli R (2019) How important is aerial leaf litter for insectivorous birds foraging in a Malaysian tropical forest? Glob Ecol Conserv 20:e00722. https://doi.org/10.1016/j.gecco.2019.e00722

McGarigal K, Cushman SA (2002) Comparative evaluation of experimental approaches to the study of habitat fragmentation effect. Ecol Appl 12(2):335 345. https://doi.org/10.1890/1051-0761(2002)012[0335:CEOEAT]2.0.CO;2

McKinney ML (2002) Urbanization, biodiversity, and conservation. BioScience 52(10):883-890. https://doi.org/10.1641/0006-3568(2002)052[0883:UBAC]2.0. $\mathrm{CO}: 2$

Michalski F, Boulhosa RLP, Faria A, Peres CA (2006) Human-wildlife conflicts in a fragmented Amazonian forest landscape: determinants of large felid depredation on livestock. Anim Conserv 9(2):179-188. https://doi.org/1 0.1111/j.1469-1795.2006.00025.x

Mohd-Taib FS, Ishak SN, Mansor MS, Md-Nor S (2018) Impacts of inundation on bird assemblages in forests in and around a hydrodam in Terengganu, Malaysia. Sains Malays 47(8):1645-1656. https://doi.org/10.17576/jsm-2018-4 708-03

Moore RP, Robinson WD, Lovette IJ, Robinson TR (2008) Experimental evidence for extreme dispersal limitation in tropical forest birds. Ecol Lett 11(9):960968. https://doi.org/10.1111/j.1461-0248.2008.01196.x

Newmark WD (1991) Tropical forest fragmentation and the local extinction of understory birds in the Eastern Usambara Mountains, Tanzania. Conserv Biol 5(1):67-78. https://doi.org/10.1111/j.1523-1739.1991.tb00389.x

Niwattanakul SJ, Naenudorn E, Wanapu S (2013) Using of Jaccard coefficient for keywords similarity. Proc Int MultiConference Engineers Comp Scientists, Hong Kong 1:380-384

Nowak S, Gutschner M, Favaro G (2003) Renewables for power generation: status and prospects. IEA, Paris

Paish O (2002) Small hydro power: technology and current status. Renew Sust Energ Rev 6(6):537-556. https://doi.org/10.1016/S1364-0321(02)00006-0

PERHILITAN (2007) Detailed environmental impact assessment report. Unpublished report.

Pleguezuelos JM, Santos X, Fernández-Cardenete JR, Caro J, Márquez-Ferrando R, Ontiveros D (2012) Recovery of the bird community after a mine spill and landscape restoration of a Mediterranean river. Restor Ecol 21:193-199

Šálek M (2012) Spontaneous succession on opencast mining sites: implications for bird biodiversity. J Appl Ecol 49(6):1417-1425. https://doi.org/10.1111/j.13 65-2664.2012.02215.x

Schweiger O, Klotz S, Durka W, Kühn I (2008) A comparative test of phylogenetic diversity indices. Oecologia 157(3):485-495. https://doi.org/10.1007/s00442008-1082-2

Şekercioḡlu CH (2002) Forest fragmentation hits insectivorous birds hard. Directions Sci 1:62-64

Slocum MG, Horvitz CC (2000) Seed arrival under different genera of trees in a neotropical pasture. Plant Ecol 149(1):51-62. https://doi.org/10.1023/A:1 009892821864
Sodhi NS, Brook BW (2006) Southeast Asian Biodiversity in Crisis. Tropical Biology Series. Cambridge University Press, Cambridge

Sodhi NS, Liow LH, Bazzaz FA (2004) Avian extinctions from tropical and subtropical forests. Annu Rev Ecol Evol Syst 35:323-345. https://doi.org/1 0.1146/annurev.ecolsys.35.112202.130209

Sohil A, Sharma N (2020) Assessing the bird guild patterns in heterogeneous land use types around Jammu, Jammu and Kashmir, India. Ecol Process 9:49. https://doi.org/10.1186/s13717-020-00250-9

Stouffer PC, Bierregaard RO Jr (1995) Use of Amazonian forest fragments by understorey insectivorous birds. Ecology 76(8):2429-2445. https://doi.org/1 $0.2307 / 2265818$

Styring AR, Ragai R, Unggang J, Stuebing R, Hosner PA, Sheldon FH (2011) Bird community assembly in Bornean industrial tree plantations: effects of forest age and structure. Forest Ecol Manag 261(3):531-544. https://doi.org/10.101 6/j.foreco.2010.11.003

Styring AR, Ragai R, Zakaria M, Sheldon FH (2016) Foraging ecology and occurrence of 7 sympatric babbler species (Timaliidae) in the lowland rainforest of Borneo and peninsular Malaysia. Curr Zool 62(4):345-355. https://doi.org/10.1093/cz/zow022

Suárez-Seoane S, Osborne PE, Alonso JC (2002) Large-scale habitat selection by agricultural steppe birds in Spain: identifying species-habitat responses using generalized additive models. J Appl Ecol 39(5):755-771. https://doi.org/10.104 6/j.1365-2664.2002.00751.x

Thiollay J (1992) Influence of selective logging on bird species diversity in a Guianan Rain Forest. Conserv Biol 6(1):47-63. https://doi.org/10.1046/j.1523-1 739.1992.610047.x

Tolimieri N, Anderson MJ (2010) Taxonomic distinctness of demersal fishes of the California current: moving beyond simple measures of diversity for marine ecosystem-based management. PLoS One 5(5):e10653. https://doi.org/10.13 71/journal.pone.0010653

USEIA (2017) US Energy Information Administration 2017. Source: https://www. eia.gov/outlooks/steo

van Houte S, Ekroth AKE, Broniewski JM, Chabas H, Ashby B, Bondy-Denomy J, Westra ER (2016) The diversity-generating benefits of a prokaryotic adaptive immune system. Nature 532(7599):385-388. https://doi.org/10.1038/nature17436

Warwick RM, Clarke KR (1995) New 'biodiversity' measures reveal a decrease in taxonomic distinctness with increasing stress. Mar Ecol Prog Ser 129:301-305. https://doi.org/10.3354/meps129301

Wolfe JD, Stouffer PC, Mokross K, Powell LL, Anciaes MM (2015) Island vs. countryside biogeography: an examination of how Amazonian birds respond to forest clearing and fragmentation. Ecosphere 6(12):295

Wong M (1985) Understorey birds as indicators of regeneration in a patch of selectively logged West Malaysian rain forest. In: Diamond AW, Lovejoy TE (eds), Conservation of tropical forest birds. ICBP Technical Publication 4:42494263

Wu H, Chen J, Xu J, Zeng G, Sang L, Liu Q, Ye S (2019a) Effects of dam construction on biodiversity: a review. J Clean Prod 221:480-489. https://doi. org/10.1016/j.jclepro.2019.03.001

Wu H, Dai J, Sun S, Du C, Long Y, Chen H, Chen J (2021) Responses of habitat suitability for migratory birds to increased water level during middle of dry season in the two largest freshwater lake wetlands of China. Ecol Indic 121 107065. https://doi.org/10.1016/j.ecolind.2020.107065

Wu HP, Chen J, Zeng GM, Xu JJ, Sang LH, Liu Q, Dai J, Xiong WP, Yuan Z, Wang YQ, Ye SJ (2019b) Effects of early dry season on habitat suitability for migratory birds in China's two largest freshwater lake wetlands after the impoundment of Three Gorges Dam. J Environ Informatics 36(2):82-92

Yong DL, Qie L, Sodhi NS, Koh LP, Peh KSH, Lee TM, Lim SLH (2011) Do insectivorous bird communities decline on land-bridge forest islands in Peninsular Malaysia? J Trop Ecol 27(1):1-14. https://doi.org/10.1017/S02664 67410000520

Zakaria BHM, Francis CM (2001) The effects of logging on birds in tropical forests of IndoAustralia. In: Fimbal RA, Grajal A, Robinson JG (eds) The cutting edge: conserving wildlife in logged tropical forests. Columbia University Press, New York

Zakaria M, Nordin M (1998) Comparison of frugivory by birds in primary and logged lowland dipterocarp forests in Sabah, Malaysia. Tropical Biodiversity 5:1-9

\section{Publisher's Note}

Springer Nature remains neutral with regard to jurisdictional claims in published maps and institutional affiliations. 